\title{
F-prime transfer and multiplication of sexduced cells
}

\author{
By P. G. DE HAAN and A. H. STOUTHAMER \\ Laboratory for Microbiology, State University, Utrecht, Holland
}

(Received 27 July 1962)

\section{INTRODUCTION}

The mating type of Escherichia coli is determined by the presence or absence of the sex factor. Cells which lack the sex factor are called recipients or females and are designated $\mathrm{F}^{-}$; cells which possess the sex factor are either $\mathrm{F}^{+}$or $\mathrm{Hfr}$. In $\mathrm{F}^{+}$strains the sex factor behaves as an autonomous, extrachromosomal particle, transmissible by conjugation (Lederberg, Cavalli \& Lederberg, 1952; Hayes, 1953 $a$ ), whereas in Hfr strains the sex factor is attached to the chromosome and only transmissible to the recipient cell as a chromosomal locus (Cavalli, Lederberg \& Lederberg, 1953; Hayes, 1953b; Richter, 1957). Jacob \& Wollman (1958) have proposed the name episome for genetic elements which have alternate states of existence either as a cytoplasmic autonomous particle or integrated on the bacterial chromosome.

From a number of $\mathrm{Hfr}$ strains recombinant sex factors ( $F$-primes) have been isolated which harbour a functional locus of the bacterial chromosome (Jacob \& Adelberg, 1959; Hirota \& Sneath, 1961). The $F$-prime is transmissible to a recipient cell as an extrachromosomal particle; converting the $\mathrm{F}^{-}$cells into donors, capable of transferring their chromosome with relatively high efficiency in the same order as in the original Hfr from which the $F$-prime was isolated. The transfer of a bacterial marker incorporated in the sex factor is called sexduction.

Restriction of the period of effective contact formation enabled de Haan \& Gross (1962) to study the kinetics of chromosome transfer in $\mathrm{Hfr} \times \mathrm{F}^{-}$crosses in more detail. In some of the mating pairs a delay of 15 minutes was found before transfer commenced. The experiments reported here were started in an attempt to detect, among mating pairs in $F$-prime $\times \mathrm{F}^{-}$crosses, a variation in the time between contact formation and the initiation of transfer of the episome. A small variation has been detected.

During the experiments some information was obtained about the multiplication of sexduced cells shortly after transfer of the episome to the recipient cell.

\section{MATERIALS AND METHODS}

(i) Bacterial strains

The $\mathrm{F}^{+}$strains employed were:

Strain $5832 M^{-} \operatorname{str}^{8}\left(F^{-} g a l^{+}\right) \quad\left({ }^{*} \mathrm{~F}_{8}\right.$, Hirota \& Sneath, 1962)

Strain $5833 M^{-} \operatorname{str}^{8}\left(F^{-} l a c^{+}\right) \quad\left({ }^{*} \mathrm{~F}_{13}\right.$, Hirota \& Sneath, 1962)

* Obtained from Dr R. C. Clowes (London). 
The $\mathrm{F}^{-}$strains employed were:

$\mathrm{P}_{678} T^{-} L^{-} B_{1}^{-}$str $^{r}$ gal $^{-}$lac $^{-} \quad$ (Jacob \& Wollman, 1956)

A $T^{+} L^{+} B_{1}^{-} s t r^{r} g a l^{-} l a c^{-}$and a $T^{+} L^{+} B_{1}^{+}$str $^{8} \mathrm{gal}^{-} \mathrm{lac}^{-}$derivative were obtained by crossing $\mathrm{P}_{678}$ with $\mathrm{Hfr} R_{4}$.

$$
\text { 58-161 } M^{-} s t r^{s} \quad \text { (Tatum, 1945) }
$$

The symbols of the markers represent:

$\begin{array}{ll}M & \begin{array}{l}\text { methionine } \\ \text { threonine } \\ \text { leucine } \\ L\end{array} \\ B_{1} & \begin{array}{l}\text { thiamine } \\ \text { gal }\end{array} \\ l a c & \begin{array}{l}\text { galactose } \\ \text { lactose } \\ s t r^{s} \text { or } s t^{r}\end{array} \\ \text { sensitive or resistant against streptomycin }\end{array}$

(ii) Media

Minimal medium was as described by Winkler \& de Haan (1948). Triphenyltetrazoliumchloride medium (TTZ): as described by Lederberg (1948) with $1 \%$ galactose or $1 \%$ lactose.

\section{(iii) Methods of crossing}

Stock cultures were maintained at $4^{\circ} \mathrm{C}$. on Dorsett egg slopes. Overnight cultures were prepared by inoculating $5 \mathrm{ml}$. of nutrient broth and incubating at $37^{\circ} \mathrm{C}$. without aeration. Fresh cultures were prepared by diluting $1 \mathrm{ml}$. of the overnight cultures into $9 \mathrm{ml}$. of prewarmed broth in screw-capped bottles. After incubating for 90 minutes on an inclined turntable the cultures were centrifuged and resuspended in $2.5 \mathrm{ml}$. prewarmed broth. The transfer of the $F$-episome was studied by the method described by de Haan \& Gross (1962) for chromosome transfer. In all experiments equal volumes of concentrated $\mathrm{F}^{+}$and $\mathrm{F}^{-}$strains were mixed to give a final concentration of about $1 \times 10^{9}$ cells per $\mathrm{ml}$.

After mixing, 10 minutes were allowed for the formation of mating pairs. The mating suspension was then diluted by a factor $5 \times 10^{5}$ in prewarmed broth. Samples from the non-rotated dilution were then withdrawn at regular intervals, and transfer was interrupted by violently shaking (blending) for 30 seconds on a microid flask shaker (Griffin \& George Ltd.). The number of sexduced cells was determined by plating $0.1 \mathrm{ml}$. samples of the blended suspension on to TTZ plates supplemented with the appropriate carbohydrate. The donor strain was killed by the addition of $100 \mu \mathrm{g} . / \mathrm{ml}$. streptomycin.

Multiplication of sexduced cells was studied by one of the following methods:

1. In liquid medium: The mating mixture was diluted by a factor $5 \times 10^{5}$ in broth 10 minutes after mixing and this suspension was blended after an additional 8 minutes. At regular intervals $0.1 \mathrm{ml}$. samples of the blended suspension were plated on TTZ plates. 
2. On solid medium : 10 minutes after mixing the mating suspension was diluted by a factor $2 \times 10^{4}$ and blended after an additional incubation for 8 minutes. Immediately after blending, pre-warmed TTZ plates were inoculated by the method of Miles \& Misra (1938) with drops of $0.008 \mathrm{ml}$. Thus forty plates could be inoculated within a period of $2-3$ minutes. The plates were incubated at $37^{\circ} \mathrm{C}$. and at regular intervals the cells on five plates were distributed with the aid of $0.1 \mathrm{ml}$. saline. In order to obtain reproducible results, it was necessary to pre-warm the plates overnight before use.

All counts are recorded as the mean of five platings. The experiments were carried out in a constant-temperature room maintained at $37^{\circ} \mathrm{C}$.

\section{(iv) Test for mating type}

A fresh culture of 58-161 $\mathrm{F}^{-}$was centrifuged, washed twice with saline and the pellet resuspended in saline (half of the original volume). Colonies from TTZ plates were inoculated into broth and grown up for a period of 4 hours. Small drops $(0.03 \mathrm{ml}$.) of the broth cultures were then spotted on minimal plates inoculated with $0 \cdot 1 \mathrm{ml}$. of the concentrated $58-161 \mathrm{~F}^{-}$suspension.

\section{RESULTS}

\section{(i) Transfer of the episome}

Figure 1 represents the results of an experiment in which the transfer of $F$-gal ${ }^{+}$ was followed. Ten minutes after mixing, the suspension was diluted and at regular intervals, thereafter, the mating pairs were broken up by blending.

It may be seen that at the moment of dilution the mixture contains already a small number of $\mathrm{gal}^{+}$cells and that 25 minutes after mixing the transfer is completed. In separate experiments in which the mating mixture was diluted and blended at earlier times, it was found that the first sexduced cells appear 4 minutes after mixing. There is thus an interval of about 21 minutes between the time of blending at which the first $\mathrm{gal}^{+}$cells can be recovered and the time when transfer of the sexfactor was completed. This result indicates that there is a small but definite asynchrony of about 11 minutes over and above that introduced by the 10 minutes period of contact formation.

A number of $\mathrm{gal}^{+}$and $\mathrm{gal}^{-}$colonies from the TTZ plates were tested for mating type with the method described earlier. It was found that all $\mathrm{gal}^{+}$cells had also received the $F$-episome, whereas all gal $^{-}$colonies were $\mathrm{F}^{-}$(Table 1 ). This experiment confirms that $F$ and gal cannot be separated by blending (Sneath, 1962).

Ten minutes after mixing, about $50 \%$ of the gal $^{+}$recombinants in the blended mixture are scored on TTZ plates as variegated colonies. The number of variegated colonies $\left(g a l_{v}^{+}\right)$first rises but before transfer is completed, a decrease is already observed.

The fall in the number of $\mathrm{gal}_{\mathrm{v}}^{+}$colonies suggests that the number of episomes per cell increases during transfer. The continuous drop in the number of $g_{a l}^{+}$colonies and the immediate multiplication of the $\mathrm{gal}^{+}$cell, after transfer is completed, 


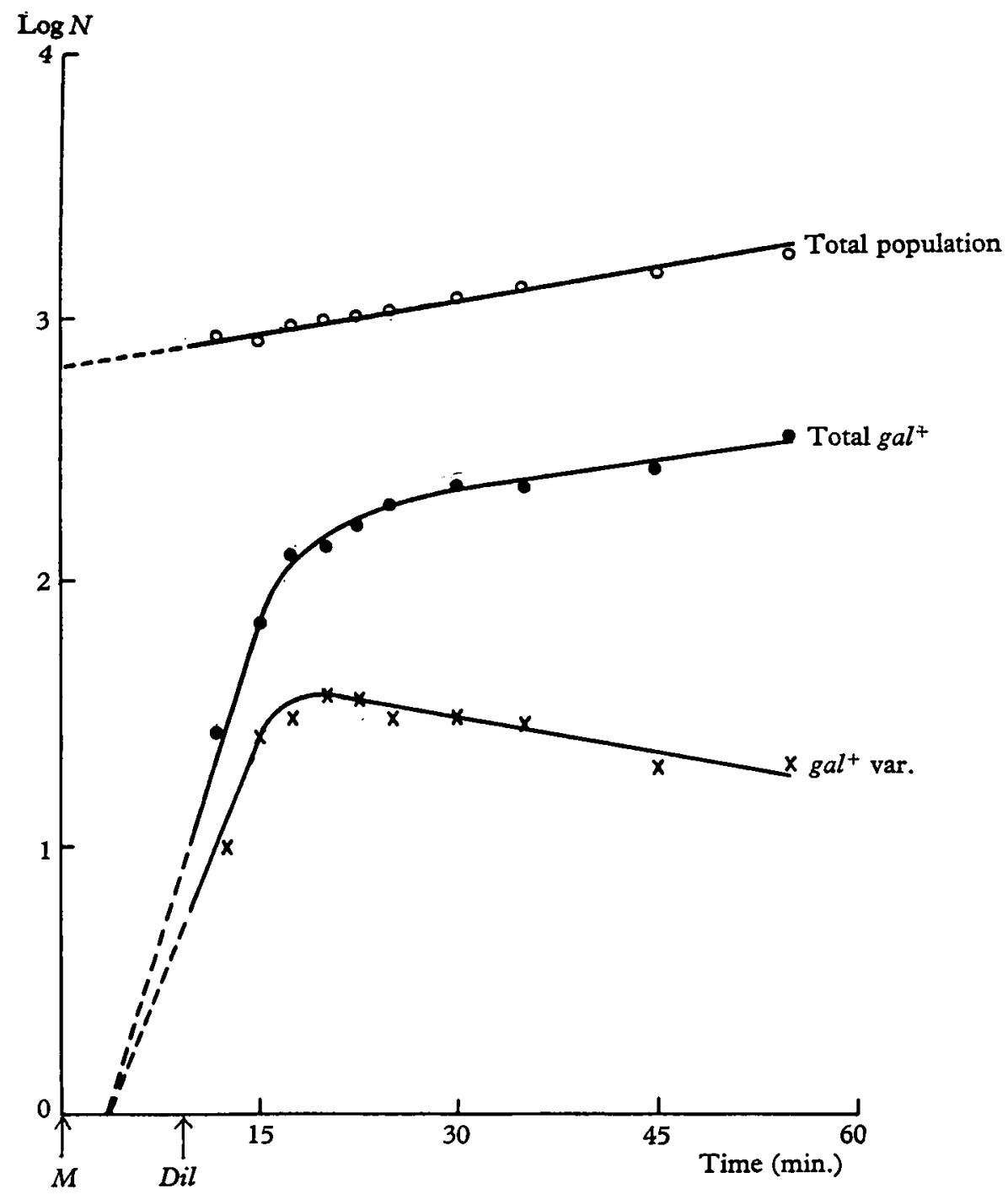

Fig. 1. Transfer curve for the $F$-gal + episome in a cross between 5832 and $P_{678}$. The mating mixture was diluted by a factor $5 \times 10^{5}$ into prewarmed broth at the time indicated by the arrow. Transfer was interrupted at intervals by blending.

$$
\begin{aligned}
& O=\text { total gal }+ \text { (pure and variegated colonies) } \\
& \mathrm{O}=\text { total population }\left(\text { gal }^{+}+\text {gal }^{-}\right) \\
& \times=\text {variegated gal }{ }^{+} \text {colonies }
\end{aligned}
$$

indicates that each $\mathrm{gal}^{+}$cell contains already two or more copies of the episome at cell division. Two factors may be responsible for this increase:

1. The generation time of the episome is small as compared with the generation time of the cell.

2. During the course of the experiment a second episome is transferred to the $\mathrm{F}^{-}$cell.

D 
The first possibility was tested by studying the multiplication of gal $^{+}$cells, which had been in contact with the donor strain for only a short period, thus limiting a possible double transfer.

Table 1. Tests for mating type.

$\begin{array}{ccccc}\begin{array}{c}\text { Time of } \\ \text { blending } \\ \text { after mixing }\end{array} & \begin{array}{c}\text { No. of } \mathrm{gal}^{+} \\ \text {tested for } \\ \text { mating type }\end{array} & \text { No. of } \mathrm{F}^{+} & \begin{array}{c}\text { No. of } \mathrm{gal}^{-} \\ \text {tested for } \\ \text { mating type }\end{array} & \text { No. of } \mathrm{F}^{-} \\ 4 & 6 & 6 & 13 & 13 \\ 5 & 8 & 8 & 87 & 87 \\ 6 & 18 & 18 & - & - \\ 8 & 22 & 22 & 2 & 2 \\ 10 & 45 & 45 & 10 & 10 \\ 15 & 34 & 34 & 10 & 10 \\ 20 & 51 & 51 & 10 & 10\end{array}$

A mating mixture of 5832 and $P_{678}$ was blended at intervals and plated on TTZ-gal-streptomycin. Colonies were grown up in broth without purification and tested for mating type versus $58-161 \mathrm{~F}^{-}$.

\section{(ii) Multiplication of gal ${ }^{+}$cells in liquid medium}

The possibility of joint transfer of several episomes into the recipient cell was limited by blending the mating mixture 8 minutes after diluting (i.e. 18 minutes after mixing). The number of $\mathrm{gal}^{-}, \mathrm{gal}^{+}$and $\mathrm{gal}_{\mathrm{v}}^{+}$cells was then followed by plating on TTZ-gal at regular intervals. Figure 2 represents the results of such an experiment. It may be seen from this figure that the total number of $\mathrm{gal}^{+}$cells increases logarithmically at the same rate as the gal $^{-}$. These results show that conjugation followed by blending has no influence on the multiplication of the recipient cell (compare Tomizawa, 1960). The immediate increase of the $\mathrm{gal}^{+}$cells indicates that, in liquid medium, the probability of segregation of $\mathrm{F}^{-} \mathrm{gal}^{-}$cells is low even at the very beginning of the experiment.

On solid medium $50 \%$ of the blended $\mathrm{gal}^{+}$cells are scored as variegated colonies. The number of variegated colonies decreases logarithmically with a 'half-life' of about 70 minutes.

The size of the $\mathrm{gal}^{-}$sectors in the variegated colonies decreases on prolonged incubation in liquid medium. The decreasing size of the $\mathrm{gal}^{-}$sectors was taken as evidence that at later times the segregation of the $\mathrm{gal}^{-}$cells occurred at later divisions. This result suggests that the number of episomes per cell increases during incubation in liquid medium. Consequently, the episome has a smaller generation time than the cell.

Dilution of the mating mixture in minimal medium instead of broth causes an even more rapid decrease in the number of $\mathrm{gal}_{\mathbf{v}}^{+}$colonies on the TTZ plates. As no multiplication of $\mathrm{gal}^{+}$and $\mathrm{gal}^{-}$cells is observed for the first hour (lag time), this experiment indicated that multiplication of the episome is, to a certain extent, independent of cell division. The same phenomenon is observed when the mating 
mixture is diluted into broth supplemented with $20 \mu \mathrm{g}$./ml. chloramphenicol. Ten minutes after dilution cell-multiplication is inhibited but the fraction of gal $_{\mathbf{v}}^{+}$ colonies continues to decrease. In both experiments the fall in the number of $\mathrm{gal}_{\mathrm{v}}^{+}$ colonies is accompanied by a decrease in sector size, confirming that sector size is related to the number of episomes per cell. Essentially similar results were obtained when the multiplication of $\mathrm{P}_{678} \mathrm{~F}_{\text {-lac }}{ }^{+}$was studied in broth. The immediate multiplication of $\mathrm{F}^{+}$cells was also observed after transfer of wild type $\mathrm{F}^{+}$from E. coli $\mathrm{K}_{12} \mathrm{~F}^{+}$to $\mathrm{P}_{678} \mathrm{~F}^{-}$.

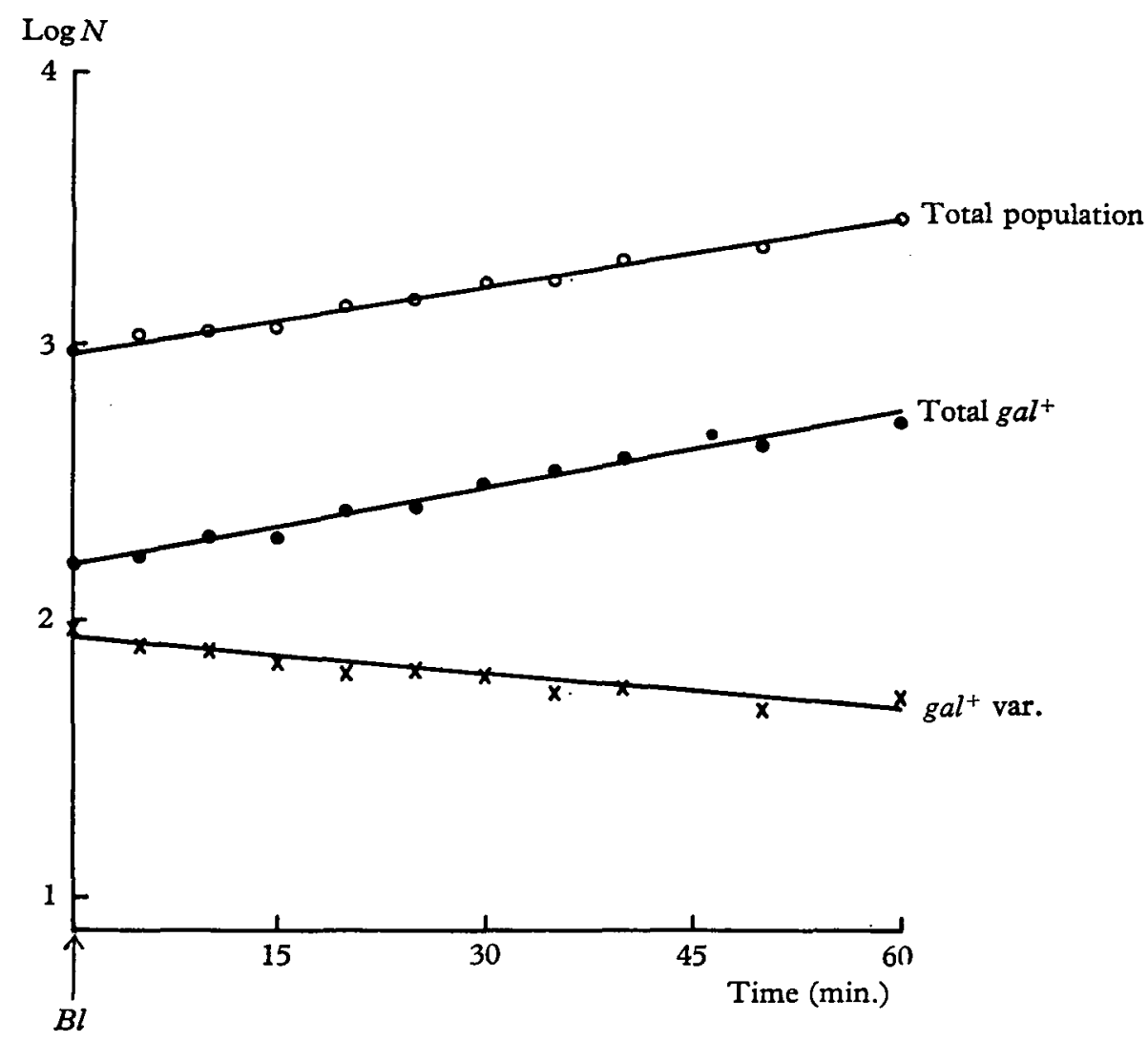

Fig. 2. Multiplication of sexduced cells in liquid medium. After 10 minutes the mating mixture of 5832 and $\mathrm{P}_{678}$ was diluted by a factor $5 \times 10^{5}$ into pre-warmed broth: 8 minutes later the diluted suspension was blended and then samples were plated at regular intervals on TTZ-gal-str plates.

$$
\begin{aligned}
& O=\text { total population } \\
& =\text { total gal+ } \\
& \times=\text { variegated gal }{ }^{+} \text {colonies }
\end{aligned}
$$

(iii) Multiplication of sexduced cells on solid medium

Sexduced cells, which in liquid medium segregate two $\mathrm{gal}^{+}$daughter cells, are scored on TTZ-gal-streptomycin plates as variegated colonies. This result strongly suggests that the behaviour of the $\boldsymbol{F}$-factor, after transfer to the recipient, varies 
according to whether the cells are in liquid or on solid medium, i.e. cells which, in liquid medium give rise to two $\mathrm{gal}^{+}$daughters, segregate $\mathrm{gal}^{-}$cells on solid medium.

The results of an experiment in which the multiplication of the $g a l^{+}$cell was studied on solid medium is shown in Fig. 3. It may be seen from this figure that the number of $\mathrm{gal}^{-}$cells increases logarithmically with a generation time of about 35 minutes. 'The number of $\mathrm{gal}^{+}$cells (pure and variegated) rises very slowly during the first 20 minutes. After about 40 minutes, the curves for $\mathrm{gal}^{-}$and $\mathrm{gal}^{+}$become

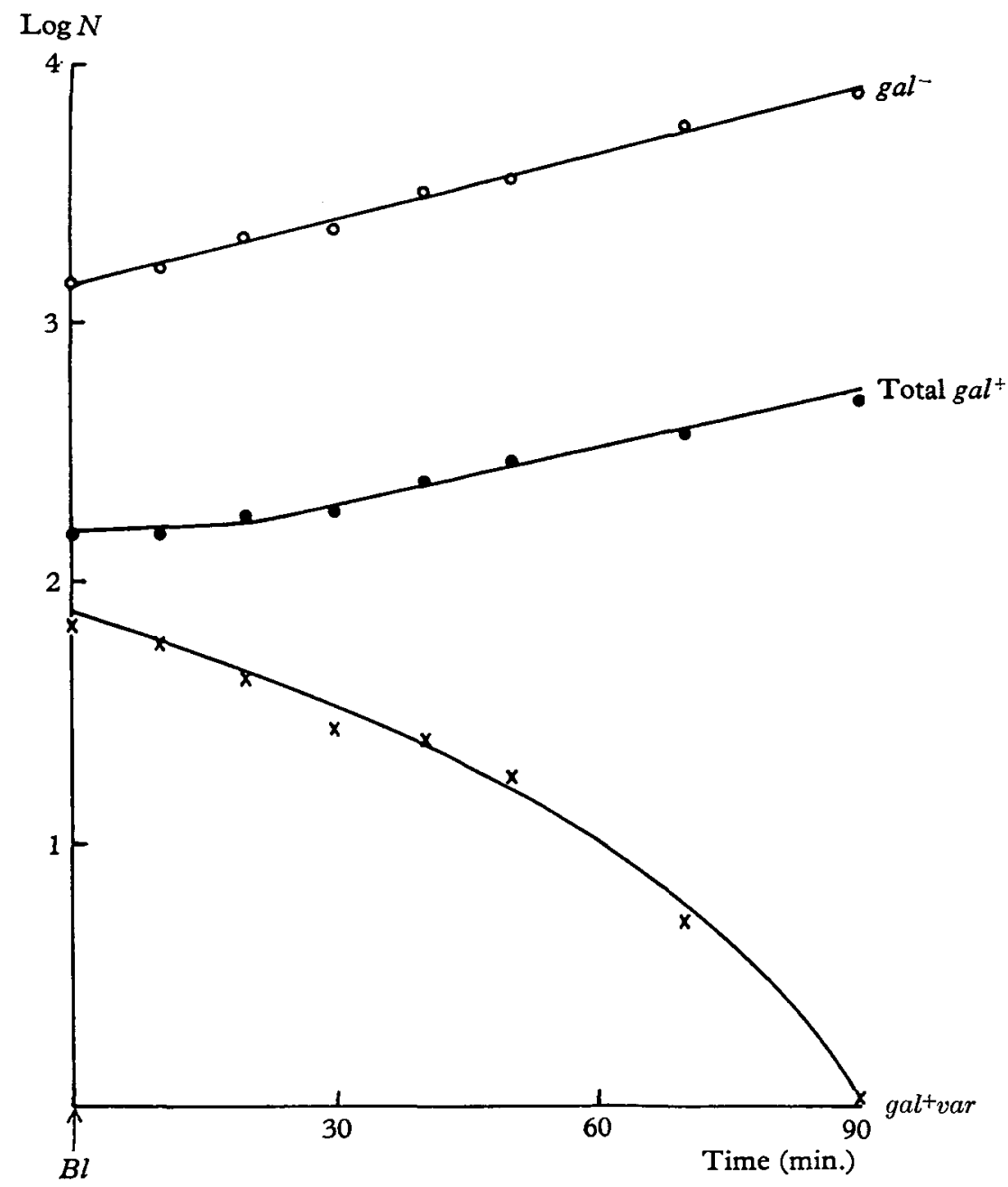

Fig. 3. Multiplication of sexduced cells on solid medium. After 10 minutes the mating mixture of 5832 and $P_{678}$ was diluted by a factor $2 \times 10^{4}$ into broth: 8 minutes later the diluted suspension was blended. TTZ-gal-str plates were inoculated with drops of $0.008 \mathrm{ml}$. At regular intervals the cells on five plates were distributed with the aid of $0.1 \mathrm{ml}$. saline.

$$
\begin{aligned}
& \mathrm{O}=\text { gal }^{-} \\
& =\text {total gal } \\
& \times=\text { variegated } \text { gal }^{+}
\end{aligned}
$$


essentially parallel, indicating that from this time on the $\mathrm{gal}^{+}$cells multiply at about the same rate as the $\mathrm{gal}^{-}$cells. The curve for the variegated colonies now is quite different from a similar curve in broth (Fig. 2). It may be noted that the fall in the number of cells on solid medium is much faster than in liquid medium. This experiment clearly indicates that during the first generation on solid medium the majority of the $\mathrm{gal}^{+}$cells segregate a $\mathrm{gal}^{-}$cell. The decreasing size of the sector in the variegated colony, which was also observed in this experiment, shows that at later times the $\mathrm{gal}^{-}$cell is thrown off in later generations, which can only be explained by the fact that the episome multiplies faster than the cell.

The possibility that the addition of TTZ, streptomycin and galactose to the solidified medium was responsible for the different behaviour of gal $^{+}$cells on solid medium was tested by repeating the experiment in liquid medium in the presence of TTZ, galactose and streptomycin. However, no lag in the multiplication of the $\mathrm{gal}^{+}$cells was found.

\section{(iv) Simultaneous transfer of episomes}

Earlier it was shown that the number of episomes per cell increases during the transfer period. Experiments in which the transfer period was limited have shown that the generation time of the episome was small as compared with the generation time of the cell. The possibility that more episomes can be transferred to one recipient cell cannot, however, a priori be excluded. This possibility was tested by studying the transfer with a donor strain carrying two different episomes.

A strain carrying two different episomes was obtained in the following way: $T^{+} L^{+} B_{1}^{+} s t r^{8} l a c^{-} g a l^{-}$was first infected with $F$-gal ${ }^{+}$and $g a l^{+}$colonies were isolated on minimal agar with galactose as the sole carbon source. One of the colonies was purified on the same medium and thereafter infected by the same method with $\mathrm{F}^{\prime}-\mathrm{lac} \mathrm{c}^{+}$. The $\mathrm{lac}^{+}$colonies obtained in this way were purified and tested on TTZ-lac and TTZ-gal plates. The majority of the $\mathrm{lac}^{+}$strains had retained the ability to ferment galactose. All isolated $\mathrm{lac}^{+} \mathrm{gal}^{+}$strains were unstable, i.e. segregated $\mathrm{lac}^{-} \mathrm{gal}^{+}$and $\mathrm{lac}^{+} \mathrm{gal}^{-}$cells. Especially $\mathrm{lac}^{-} \mathrm{gal}^{+}$cells were found with relatively high frequency. The segregation of these two types was taken as evidence that both bacterial markers are episome-bound.

Attampts to detect the transfer of $F^{-}-l a c^{+}$to $\mathrm{P}_{678} F_{-}-g a l^{+}$on TTZ-lac-str plates were less successful. It was found, in accordance with the result of Scaife \& Gross (1962), that the introduction of $F$-lac ${ }^{+}$caused the segregation of the two episomes among the daughters, giving a variegated colony, one part being $\mathrm{lac}^{+} \mathrm{gal}^{-}$and the other part $\mathrm{lac}^{-} \mathrm{gal}^{+}$. Only very seldom was a strain isolated which carried both episomes. Gross \& Scaife (personal communication) obtained similar results. The selection on minimal medium with lactose as the carbon source favours the growth of those $\mathrm{lac}^{+}$cells which are also $\mathrm{gal}^{+}$(Stouthamer \& de Haan, unpublished). Thus $\mathrm{lac}^{+} \mathrm{gal}^{+}$strains are easily isolated on minimal medium.

Fresh cultures of a $\mathrm{lac}^{+} \mathrm{gal}^{+} \mathrm{str}^{8}$ strain were always made from a white colony on a TTZ-lac plate. The suspension was incubated for a period of 4 hours.

Simultaneous transfer of both episomes was tested in the following way: a 
mixture of the $\mathrm{lac}^{+}$gal ${ }^{+}$strain and $\mathrm{P}_{678} T^{+} L^{+} B_{1}^{-}$lac $^{-}$gal $^{-}$str ${ }^{r}$ was diluted one thousand-fold 10 minutes after mixing and blended after an additional period of 30 minutes. Samples of this suspension were then plated on minimal agar supplemented with $\mathrm{B}_{1}$, streptomycin and lactose or galactose as the sole carbon source. About eighty times as many colonies were observed with galactose as the carbon source as compared with lactose.

The large majority of the $\mathrm{gal}^{+}$colonies were $\mathrm{lac}^{-}$. All $\mathrm{lac}^{+}$colonies were also $\mathrm{gal}^{+}$, which again may be due to the fact that $l a c^{+} \mathrm{gal}^{-}$cells do grow, though very poorly on minimal medium with lactose as the carbon source. The $\mathrm{lac}^{+} \mathrm{gal}^{+}$strains obtained in this way were again unstable. The segregation of $\mathrm{lac}^{-} \mathrm{gal}^{+}$and $\mathrm{lac}^{+} \mathrm{gal}^{-}$ cells indicated that both bacterial markers were episome-bound and therefore were transferred by episomes. This experiment shows that during conjugation the transfer of more than one episome is possible. However, the frequency of simultaneous transfer is probably too low to contribute significantly to the observed increase in the number of episomes per cell during the transfer period.

\section{DISCUSSION}

By limiting the period of contact formation, de Haan \& Gross (1962) were able to demonstrate among mating pairs a variable delay between the time of effective contact-formation and the initiation of chromosome transfer. In the present paper it was demonstrated that $F$-prime transfer shows about the same spread as chromosome transfer. The similarity in both results seems to indicate that the transfer lag is not related to DNA synthesis as was suggested by de Haan \& Gross (1962) but represents something non-specific like the formation of conjugation tubes (Anderson, Wollman \& Jacob, 1957).

In $\mathrm{Hfr} \times F^{-}$crosses, the entrance of the sex factor, which is located at the tail end of the chromosome, is prevented by spontaneous or artificial interruption of conjugation. Thus, bacterial markers and sex factor can be separated. In experiments with $F_{-}$-gal ${ }^{+}$, both $F$ and $g a l$ were found 4 minutes after mixing. All cells received $F$ and $g a l$ irrespective of the time of contact before the mating pairs were broken up. This experiment is in accordance with the results of Sneath (1962). The experimental evidence indicated that, with the technique used, episome and bacterial marker cannot be separated. It is known that the size of chromosomal segment, which is incorporated into the sex factor, is generally small as compared with the total length of the chromosome (Jacob \& Adelberg, 1959; Jacob \& Wollman, 1961; Hirota \& Sneath, 1962). Thus the bacterial segment which is distal to the gal genes might be too small to allow the detection of a separation of $F$ and gal. In similar experiments with $F$-lac ${ }^{+}$, separation of $F$ and $l a c$ could not be obtained. Hirota \& Sneath (1961) working with the same $F$-prime have shown that the separation of a purine marker and an episome is possible. The separation of $F$ and $l a c$, however, could not be obtained in a blender experiment.

During episome transfer the fraction of $\mathrm{gal}^{+}$cells, which gives a variegated colony on solid medium decreases. This result indicates an increase in the number 
of episomes per cell during the period of actual transfer of the sex factor. There are two possible explanations for this phenomenon:

(i) the donor transfers more than one sexfactor to the recipient cell, or

(ii) the transferred episome multiplies faster than the recipient cell.

Experiments with a strain carrying two different episomes $\left(\mathrm{F}^{-} \mathrm{lac}^{+}\right.$and $\left.\mathrm{F}^{-}-\mathrm{gal}^{+}\right)$ seem to indicate that more than one episome can be transferred to one recipient cell. The frequency of joint transfer however, was probably too small to explain the increase in the number of episomes per cell during the period of transfer.

The second explanation was tested by studying the multiplication of $\mathrm{gal}^{+}$cells in liquid medium in more detail. The number of episomes transferred to the recipient cells was restricted by blending the mating mixture 18 minutes after mixing (Fig. 2). At the beginning of the experiment, a large fraction of the $\mathrm{gal}^{+}$cells $(50 \%)$ gave rise to a variegated colony when plated on solid medium. This fact may be taken as evidence that the number of episomes per cell is still small. After 60 minutes about $10 \%$ of the $\mathrm{gal}^{+}$cells were still scored as variegated colonies. In similar experiments it was sometimes found that the decrease in the fraction of gal $_{\mathbf{v}}^{+}$colonies was even less rapid. Thus at the end of the experiment $\mathrm{gal}^{+}$cells still segregate $\mathrm{gal}^{-}$cells on solid medium. This result strongly suggests that during the whole experiment the number of episomes per cell is relatively small.

This result is in accordance with the findings of Jacob, Schaeffer \& Wollman (1960) who calculated the number of episomes per cell from the amount of $\beta$ galactosidase present in $F-l a c^{+}$cells. It was found that three copies of the episome were present in each cell.

The decreasing size of the sectors in the variegated colonies and the decrease in the fraction of variegated colonies with time show that the number of episomes per cell increases during incubation in liquid medium. Thus episome multiplication is faster than cell multiplication during the time following transfer of the episome.

In liquid medium no lag in the multiplication of $\mathrm{gal}^{+}$cells was observed (Fig. 2). Similar results were obtained with $F^{\prime}$-lac ${ }^{+}$and wild type $F$. Thus the probability of segregating a $\mathrm{F}^{-} \mathrm{gal}^{-}$cell in liquid medium is low even at the beginning of the experiment when the number of episomes per cell is very small. The autonomous extrachromosomal $F$-factor is thought to be randomly distributed among the daughter cells (Sneath, 1962). Under the assumption of random distribution, the low probability for the segregation of $\mathrm{F}^{-} \mathrm{gal}^{-}$cells strongly suggests that the $\mathrm{gal}^{+}$ cells should contain a relatively high number of episomes. This conclusion is in contradiction to the conclusion drawn from the fraction of variegated colonies obtained on solid medium. This contradiction cannot be explained by the lag in the multiplication of $\mathrm{gal}^{+}$cells which was observed on solid medium. Thus the experiments suggest that, in liquid medium, both daughter cells each obtain at least one copy of the episome, irrespective of the fact that the number of episomes per cell never reaches a value high enough to give a low probability for the random segregation of $\mathrm{gal}^{-}$cells.

The experiment in liquid medium points to a non random distribution of the 
episomes among the progeny. This non random distribution may be explained in the following way:

The fertility factor has some affinity for the bacterial chromosome. This affinity is expressed by the fact that the $F$-episome sometimes mobilizes the chromosome, converting the cell into a donor. For wild-type $F$ a mobilization efficiency of 0.05

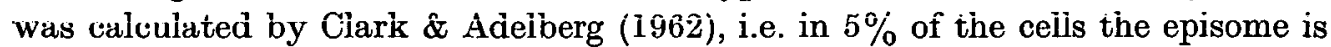
more or less firmly attached to the chromosome and the circular chromosome is opened enabling the cell to donate its chromosome to an acceptor cell. A less firmly (temporary) attachment of the episome, not accompanied by opening of the circular chromosome, cannot a priori be excluded, however.

If this assumption is correct and at cell division the large majority of the chromosomes have one attached episome, then the distribution of the episomes among the progeny is no longer random. As a consequence each daughter cell then obtains one episome although the number of episomes per cell is small.

On solid medium, a lag in the multiplication of $\mathrm{gal}^{+}$cells was found (Fig. 3). The observed lag may be due to the fact that on solid medium the multiplication of the episome is inhibited for about one generation, increasing the probability that no episome is available for one of the daughter cells. On the other hand, a shift from non random distribution in liquid medium to a (temporary) random distribution on solid medium explains the observed lag as well. No experimental conditions were found which caused the different behaviour of the $\mathrm{gal}^{+}$cells in liquid or on solid medium.

The authors are greatly indebted to Professor Dr K. C. Winkler for many helpful discussions and to Miss H. S. Felix and Miss A. K. Mol for excellent technical assistance.

\section{SUMMARY}

A variable delay among mating pairs in the time between contact formation and the initiation of $F$ transfer was found. The conjugation process has no effect on the multiplication of the recipient cell.

In liquid medium newly infecting $F$-particles multiply faster than the host cell.

The experiment strongly suggests that the number of episomes per cell is small and that the distribution of the $F$-factor among the daughter cells is non-random.

\section{REFERENCES}

Anderson, T. F., Wollman, E. L. \& Jacob, F. (1957). Sur les processus de conjugaison et de recombinaison chez Escherichia coli. III. Aspects morphologiques en microscopie électronique. Ann. Inst. Pasteur, 93, 450-455.

Cavalli, L. L., Lederberg, J. \& Lederberg, E. M. (1953). An infective factor controlling sex compatibility in Bacterium coli. J. gen. Microbiol. 8, 89-103.

Clark, A. J. \& Apelberg, E. A. (1962). Bacterial conjugation. In: Ann. Rev. Microbiol. $16,289-320$.

HaAN, P. G. DE \& Gross, J. (1962). Transfer delay and chromosome withdrawal during conjugation in Escherichia coli. Genet. Res. 3, 251-272.

HAYES, W. (1953a). Observations on a transmissible agent determining sexual differentiation in Bact. coli. J. gen. Microbiol. 8, 72-88. 
HaYes, W. (1953b). The mechanism of genetic recombination in Escherichia coli. Cold Spr. Harb. Symp. quant. Biol. 18, 75-93.

Hirota, Y. \& Sneath, P. H. A. (1961). Jap. J. Genet. 36, 307.

$\mathrm{J}_{\triangle \mathrm{COB}}, \mathrm{F}$. \& ADELBERG, E. A. (1959). Transfert de caractères génétique par incorporation au facteur sexuel d'Escherichia coli. C. R. Acad. Sci., Paris, 249, 189-191.

JaCOB, F., SchaffFer, P. \& Wollman, E. L. (1960). Episomic elements in bacteria. In: Microbial Genetics, pp. 67-91. Cambridge University Press.

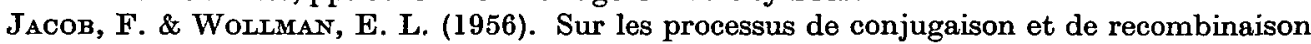
chez Escherichia coli. I. L'induction par conjugaison ou induction zygotique. Ann. Inst. Pasteur, 91, 486-510.

JACOB, F. \& Wollman, E. L. (1958). Les épisomes, éléments génétiques ajoutés. C. R. Acad. Sci., Paris, 247, 154-156.

JACOB, F. \& Wollman, E. L. (1961). In: Sexuality and the Genetics of Bacteria, p. 196. Academic Press, New York, London.

LeDerberg, J. (1948). Detection of fermentative variants with tetrazolium. J. Bact. 56, 695.

Lederberg, J., Cavalit, L. L. \& Lederberg, E. M. (1952). Sex compatibility in Escherichia coli. Genetics, 37, 720-730.

Mrtes, A. \& Misra, S. (1938). The estimation of the bactericidal power of the blood. J. Hyg., Camb., 38, 732-749.

RiChTER, A. (1957). Complementary determinants of an Hfr phenotype in $E$. coli $K_{12}$. Genetics, 42, 391.

ScaIfe, J. \& Gross, J. D. (1962). Inhibition of multiplication of an F-lac factor in Hfr cells of Escherichia coli $\mathrm{K}_{12}$. Biochem. Biophys. Res. Comm. 7, 403-407.

SNeAth, P. H. A. (1962). Sex factors as episomes. Brit. med. Bull. 18, no. 1, 41-45.

TAтUM, E. L. (1945). X-ray induced mutant strains of Escherichia coli. Proc. nat. Acad. Sci., Wash., 31, 215-219.

Tomizawa, J. I. (1960). Genetic structure of recombinant chromosomes formed after mating in Escherichia coli $\mathrm{K}_{12}$. Proc. nat. Acad. Sci., Wash., 46, 91-101.

WINkLER, K. C. \& HAAN, P. G. DE (1948). On the action of sulfanilamide. XII. A set of noncompetitive sulfanilamide antagonists for Escherichia coli. Arch. Biochem. 18, 97-107. 